\title{
Insulin Therapy in Type 3c Diabetes-More Common in Chronic Rather than Acute Pancreatitis
}

\author{
1. WILLIAM HINTON, \\ 2. MICHAEL FEHER, \\ 3. NEIL M. MUNRO, \\ 4. RACHEL M. COYLE and \\ 5. SIMON DE LUSIGNAN
}

\pm Author Affiliations

Diabetes 2018 Jul; 67(Supplement 1): -. https://doi.org/10.2337/db18-1047-P

\begin{abstract}
Background and Aims: Prevalence of diabetes following pancreatic disease (type $3 \mathrm{c}$ diabetes/T3cDM) is estimated to affect $5-10 \%$ of people with diabetes in Western populations. However, misclassification of T3cDM is common. Consequently, there is little real-world data on prescribing of antihyperglycaemic medications in people with T3cDM. The aim of this study is to evaluate prescribing of antihyperglycaemic medications in people with T3cDM.
\end{abstract}

Methods: A cohort of adults with a diagnosis of pancreatitis preceding diabetes, i.e., probable T3cDM, were identified from primary care records in England, the Royal College of General Practitioners Research and Surveillance Centre database $(\mathrm{N}=1,595,445)$. The cohort was divided into those with acute (AP) or chronic pancreatitis (CP). People who presented initially with AP and subsequently developed $\mathrm{CP}$ were categorised as the latter. We performed retrospective analyses to compare the proportions of antihyperglycaemic medications prescribed in these subgroups. Chi square $\left(\mathrm{X}^{2}\right)$ tests were used to test for differences between proportions.

Results: Of the 45,615 people living with diabetes, we identified $725(1.6 \%)$ with pancreatitis preceding their diagnosis $(\mathrm{AP}=456 ; \mathrm{CP}=269)$. The majority of those affected were prescribed non-insulin therapies $(74.8 \%)$. Metformin was the most commonly prescribed medication $(56.4 \%)$, followed by sulfonylureas (28.3\%), insulin $(25.2 \%)$ and DPP-4 inhibitors (11.6\%). People with AP were more likely to be prescribed metformin $(63.2 \%$ vs. $45.0 \% ; \mathrm{p}<0.001)$ and DPP-4 inhibitors $(13.6 \%$ vs. $8.2 \%, \mathrm{p}=0.037)$ than those with $\mathrm{CP}$, whilst people with $\mathrm{CP}$ were more likely to be prescribed insulin $(34.9 \%$ vs. $19.5 \%$; $\mathrm{p}<0.001)$. No differences in prescribing were found for other antihyperglycaemic medication classes. 
Conclusion: The differences in prescribing in people with CP compared to AP suggests progressive pancreatic damage and loss of endocrine function, with more patients requiring insulin therapy.

Disclosure W. Hinton: Other Relationship; Self; Eli Lilly and Company, Novo Nordisk Limited. M. Feher: Advisory Panel; Self; Novo Nordisk Limited, Sanofi, AstraZeneca. N.M. Munro: None. R.M. Coyle: None. S. de Lusignan: Other Relationship; Self; Eli Lilly and Company, Novo Nordisk Limited, AstraZeneca.

- $\quad$ C 2018 by the American Diabetes Association.

http://www.diabetesjournals.org/content/license

Readers may use this article as long as the work is properly cited, the use is educational and not for profit, and the work is not altered. More information is available at http://www.diabetesjournals.org/content/license. 